\title{
60 Jahre adhäsion KLEBEN+DICHTEN
}

\section{Liebe Leserin, lieber Leser,}

vor 60 Jahren startete die adhäsion KLEBEN+DICHTEN mit ihrer Berichterstattung über mineralische, pflanzliche, tierische und synthetische Kleb-, Verdickungsund Bindemittel aller Art. Heute präsentiert sie sich als moderne Fachinformationsquelle der industriellen Kleb- und Dichttechnik. Das möchten wir mit dieser Ausgabe redaktionell gebührend würdigen.

Die adhäsion KLEBEN+DICHTEN spiegelt die Entwicklung der Kleb- und Dichttechnik wider und hat sich seit Bestehen laufend - sowohl inhaltlich als auch optisch - der aktuellen Branchenentwicklung angepasst. Wie sich das äußere Erscheinungsbild des Magazins im Laufe der Zeit wandelte, zeigt unsere Chronik der Veränderungen ab Seite 10. Und mit welchen Themen man sich früher im Vergleich zu heute beschäftigt hat, beschreibt Prof. Andreas Hartwig in seinem Jubiläumsbeitrag ab Seite 14. Interessant sind außerdem die Recherchen des Industrieverband Klebstoffe ab Seite 12. Demnach gestaltete sich die heute so wunderbare Zusammenarbeit mit dem Verband anfangs ein wenig holprig.

Verändert haben sich nicht nur Aussehen und Inhalte unserer adhäsion, sondern auch die Werkzeuge der Informationsvermittlung. So ist die adhäsion KLEBEN+DICHTEN schon lange crossmedial aufgestellt, d. h. sie erreicht ihre branchenübergreifende Zielgruppe über das Printmedium, über ein interaktives E-Magazin, unseren Newsletter und über das Wissensportal Springer Professional. Das gesamte Team der adhäsion KLEBEN+DICHTEN freut sich über die lange Tradition unserer Fachzeitschrift, aber auch auf zukünftige Herausforderungen, die es mit Sicherheit zu bewältigen gibt - allerdings zukünftig ohne mich. Diese Ausgabe ist die letzte, die unter meiner Verantwortung erscheint. Nach über 22 Jahren als Chefredakteurin verabschiede ich mich von Ihnen in den Ruhestand. Es war eine wunderbare und spannende Zeit, aber ich freue mich auch auf ein Leben ohne Kleben.

Zum Schluss bleibt mir nur noch, danke zu sagen: Ich danke allen Gratulanten für ihre wertschätzenden Worte zum Jubiläum in dieser Ausgabe (Seite 6). Im Namen des gesamten Teams danke ich außerdem den Anzeigenkunden, der Leserschaft und allen Autoren, die durch ihre Treue und kompetenten Beiträge dieses Jubiläum erst möglich gemacht haben. Nicht zuletzt möchte ich mich herzlich bei meinen Kolleginnen und Kollegen für die immer tolle und angenehme Zusammenarbeit bedanken.

Der neuen Chefredaktion wünsche ich gutes Gelingen beim Weiterentwickeln der adhäsion KLEBEN+DICHTEN, die mehr als 22 Jahre lang ein wichtiger Teil meines Lebens war.

Bleiben Sie der adhäsion KLEBEN+DICHTEN wohlwollend verbunden.

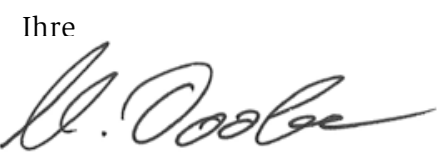

Marlene Doobe

marlene.doobe@springer.com

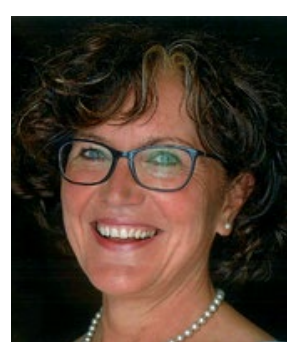

